\title{
Experimental study of aluminium honeycomb behaviour under dynamic multiaxial loading
}

\author{
R. Tounsi ${ }^{1,2}$, B. Zouari ${ }^{1}$, F. Chaari², G. Haugou'², E. Markiewicz², and F. Dammak ${ }^{1}$ \\ ${ }^{1}$ National Engineering School of Sfax, U2MP, BP. W3038, Sfax, Tunisia \\ 2 University of Valenciennes and Hainaut-Cambresis. LAMIH, UMR 8201-CNRS, 59313 Valenciennes, France
}

\begin{abstract}
Split Hopkinson Pressure Bar system (SHPB) with large-diameter and Nylon bars introducing a shear-compression loading device is used in order to investigate the dynamic behaviour of aluminium honeycomb under multiaxial loadings conditions. All shear-compression configurations including the loading angle variation from $0^{\circ}$ to $60^{\circ}$ are performed with an impact velocity of about $15 \mathrm{~m} / \mathrm{s}$. The adapted SHPB system with the device are validated numerically and a phenomenon of separation between the input bar and the input beveled bar is observed. Numerical results suggest that this phenomenon provides a cutting of the reflected wave. An electro optical extensometer is employed in experiments. A good agreement between the numerical elastic waves and the experimental ones is obtained. Experimental results show a significant effect of the loading angle on the apparent stress-strain curves. The initial peak value and the plateau stress decrease with the increase of the loading angle. The combined shear-compression device with an enhancement at the alignment set-up provides efficient results for samples dynamically loaded. This device will be used to investigate the influence of the in-plane orientation angle on the deformation mechanisms and multiaxial behaviour of aluminium honeycomb under dynamic and quasi-static loading conditions.
\end{abstract}

\section{Introduction}

Cellular materials such as honeycombs combine high energy absorption capacity and low density. The use of these materials in the field of transports contributes to improve the sustainability by reducing vehicle mass while maintaining the same safety level, and contributes to ensure passengers safety during crash events. Several studies have been performed by many authors such as Gibson and Ashby [1,2]; Yang and Huang [3], Wu and Jiang [4]; Zhao and Gary [5]; Zhao et al. [6]; Doyoyo and Mohr [7] to understand the mechanical quasi-static and dynamic behaviour of these kind of material such as aluminium honeycombs that used for energy absorption application.

The experimental investigations reported in the literatures are limited to uniaxial compressive loading. However, in the real crush event shear and compression are combined. Therefore, understand the multiaxial behaviour of such kinds of materials is necessary. A few numbers of investigations developed by Mohr and Doyoyo [8,9] and Hong et al. [10] are focus on the aluminium honeycomb behaviour under quasi-static combined shear-compression loading. Under dynamic multiaxial loading conditions, some works are reported by Hong et al. [11] and recently Hou et al. $[12,13]$. They have been investigated numerically and experimentally the honeycomb behaviour under both case quasi-static and dynamic multiaxial loading conditions.

A test device developed by Hong et al. [11] has been realized in order to investigate the honeycomb dynamic multiaxial behaviour but this method suffers from poor measurement accuracy at higher loading rates. For this raison, a new combined shear-compression method using a large-diameter Nylon Split Hopkinson Pressure Bars (SHPB) set-up is adapted by Hou et al. [12,13].

In this paper, this new testing method is used to perform the dynamic multiaxial tests using a large diameter
( $\varnothing=60 \mathrm{~mm}$ ) Nylon bars. It is based on two short beveled bars inclined with different angle in order to achieve five loading angle from $0^{\circ}$ to $60^{\circ}$ by $15^{\circ}$. The same material and diameter as the Hopkinson bars is used. FEM study is performed at the whole loading system in order to make sure of measurements accuracy given by the introducing beveled bars on the SHPB system. Virtual tests are performed at the loading angle $\Psi=0^{\circ}$ (axial case) in order to valid this processing data method with and without beveled bars.

All the tests are carried out at impact velocity around $15 \mathrm{~m} / \mathrm{s}$. Following this numerical study, some ameliorations are preformed in the test set-up in order to have an efficient accuracy on the results and investigate the effect of the in-plane orientation $\beta$ (angle between the shear load direction and the double wall thickness direction) that is not reported by Hou et al. [12,13].

\section{Enhancement of the combined shear-compression device by FEM}

Based on the combined shear-compression device developed by Hou et al. $[12,13]$ introduced in the basis SHBP system, a numerical tests are performed. Ours objectives are to make sure of the accuracy of the measurements data and the deformation mechanisms. We observe that in all loading cases especially in the most severe case (the loading angle $60^{\circ}$ ) the two short beveled are no longer aligned during the crash test. One way is to rigidify the sleeve that guides the two short bars without any effect on the data measurements and final results.

The combined shear-compression loading device such as defined by Hou et al. $[12,13]$ is composed by two short cylindrical bars with one bevel end, a Teflon sleeve and two aluminium supports (figure 1). A Teflon sleeve with $20 \mathrm{~mm}$ of thickness is used to ensure the alignment and the 


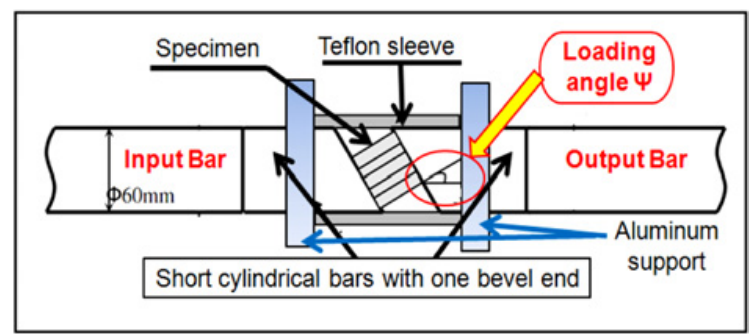

Fig. 1. Scheme of the combined shear-compression device [12].

no deviation of the short beveled. Two aluminium supports are used to fix the device in the SHBP system.

The specimen is placed between the two short beveled bars. To respect the wave propagation low from the input/output bars to the input/output beveled bars without any significant reflections or effects. The two beveled bars have the same material and diameter of the Hopkinson bars.

The same measuring method with classical Hopkinson system with large diameter and viscoelastic bars is used. This method based on the one-dimensional elastic wave theory has been validated by Zhao and Gary [14]. But the introduction of the combined shear-compression device on the SHPB system can be caused the friction between the Teflon sleeve and the beveled bars and an error on the displacement measurement of specimens. In fact, some assumptions are needed to valid the using of this device to achieve the multiaxial behaviour of cellular materials under dynamic loading conditions. In order to verify those two assumptions suggested by Hou et al. $[12,13]$, a numerical study of the complete loading system (device and SHBP) is carried out.

When we simulate the loading system in the case dynamic combined shear-compression loading, we observe that the Teflon sleeve swells causing a bad alignment of the short beveled bars during the experiments.

\subsection{FE model}

The finite element model is composed by a projectile, two input and output Hopkinson bars and a combined shear-compression loading device. The components of this device are two short beveled bars, a Teflon sleeve, a Steel sleeve, two supports and the specimen. To validate the efficiency of the whole system, the most severe case with loading angle $\Psi=60^{\circ}$ is established. The same dimensions of all part of the loading system are used.

8-node linear brick elements with reduced integration (C3D8R) are used. The element size is $5 \mathrm{~mm}$ for the bars, the sleeves and supports, while $3 \mathrm{~mm}$ for the bevels and $1.5 \mathrm{~mm}$ for the specimen (figure 2). For the specimen, the constitutive behaviour is described by a crushable foam model, here you give the most important behaviour is the plastic that dominates the elastic behaviour (table1).

For the projectile, bars and beveled bars, linear material with elastic constants of Nylon is used. For the Teflon sleeve, Steel sleeve and supports, linear material with elastic constants of Teflon, Steel and Aluminium respectively is used. The material proprieties are listed in table 2.

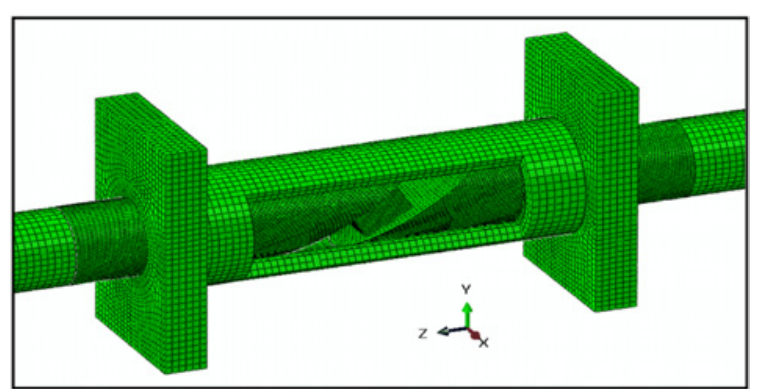

Fig. 2. Finite element model of SHPB with combined shear-compression loading device.

Table 1. Honeycomb material properties.

\begin{tabular}{|l|c|}
\hline & Honeycomb \\
\hline Density $\rho(\mathrm{kg} / \mathrm{m} 3)$ & 82.6 \\
\hline Young's Modulus E (MPa) & 450 \\
\hline Poission's Ratio $v$ & 0.35 \\
\hline Plastic Possion's Ratio $v \mathrm{p}$ & 0 \\
\hline Yield Stress $\sigma$ s $(\mathrm{MPa})$ & 3.22 \\
\hline Lock Strain $\varepsilon$ lock & 0.72 \\
\hline
\end{tabular}

Table 2. The material proprieties of Nylon, Teflon, Steel and Aluminium.

\begin{tabular}{|l|c|c|c|}
\hline & $\begin{array}{c}\text { Density } \rho \\
\left(\mathrm{kg} / \mathrm{m}^{3}\right)\end{array}$ & $\begin{array}{c}\text { Young's Modulus } \\
\mathrm{E}(\mathrm{MPa})\end{array}$ & $\begin{array}{c}\text { Poission's } \\
\text { Ratio } v\end{array}$ \\
\hline Nylon & 1120 & 3370 & 0.3 \\
\hline Teflon & 2200 & 1500 & 0.46 \\
\hline Steel & 7800 & 210000 & 0.295 \\
\hline Aluminium & 2700 & 70000 & 0.35 \\
\hline
\end{tabular}

Surface to surface contact is defined between the interface of projectile/Hopkinson input bar and Hopkinson bars/beveled bars with frictionless contact property. At the interfaces between the specimen and the beveled bars, surface-to-surface contact with penalty contact method is applied. A Coulomb friction coefficient is equal to 0.5 . The penalty contact method is applied between the Steel sleeve, the Teflon sleeve and the Nylon bars with a friction coefficient are set to be 0.05 .

The real impact velocity measured in the experiment is $15 \mathrm{~m} / \mathrm{s}$ that used to initialise the velocity of the projectile in axial ( $\mathrm{Z}$ ) direction. The bottom surface of the two supports is restricted on three translational displacements and rotations that correspond to the realistic boundary loading conditions. Two elements located on the external surface of the input and output bars corresponding to the positions of strain gauges are picked. The position of the strain gauges is shown in figure 3 with the SHPB set-up.

The software ABAQUS/Explicit is used to simulate the numerical crash tests with the adopted SHPB set-up.

\subsection{FE model results}

A numerical study is performed in order to investigate the effect of the Teflon and Steel Sleeves on the sequence of tests. A convergence study on sleeves thickness shows that 


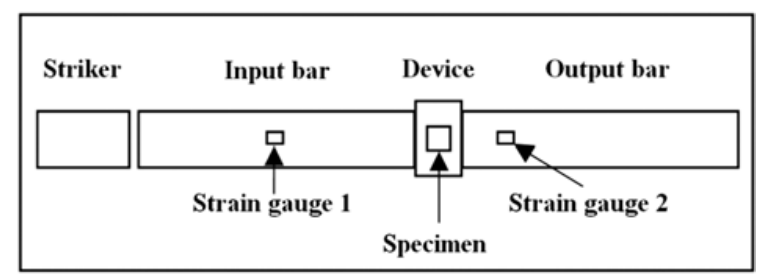

Fig. 3. The SHPB set-up and the strain gauge positions.

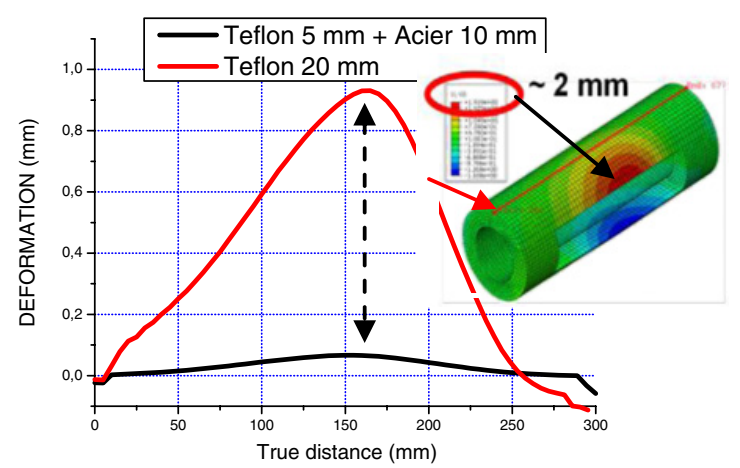

Fig. 4. The sleeve rigidifying: the swelling of the Teflon $(20 \mathrm{~mm})$ and the Teflon + Acier $(5 \mathrm{~mm}+10 \mathrm{~mm})$ sleeves during the crash.

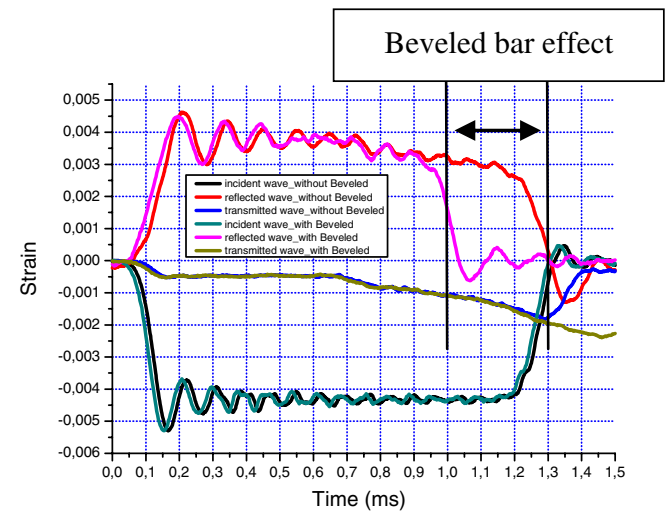

Fig. 5. The three elastic waves with and without beveled bars under axial loading $\left(\Psi=0^{\circ}\right)$.

the use of a Teflon sleeve with an aluminium sleeve needed an important thickness for obtaining a good alignment of the beveled during the test. Some numerical tests provide that a thickness of $5 \mathrm{~mm}$ of Teflon sleeve and $10 \mathrm{~mm}$ of Steel sleeve gives a deformation at the top of $0.06 \mathrm{~mm}$ smaller than $1 \mathrm{~mm}$ with only one Teflon sleeve $(20 \mathrm{~mm})$. At the window the two sleeves ensures a deformation of $0.13 \mathrm{~mm}$ and this is so smaller comparing to $2 \mathrm{~mm}$ with only one Teflon sleeve. These two sleeves thicknesses provide a good alignment during the crash test and ensure the no deviation of the two short bevelled bars during test (figure 4).

A separation at the interface of the Hopkinson input bar and the input beveled bar was observed. This phenomenon provides a cut in the reflected wave. The strain input and output pulses are recorded in the case of axial loading with and without beveled. They are separated to show each wave only (figure 5). A delay in return of the wave is observed. The reflected wave has a short duration as the incident wave and that it causes a restriction of the data

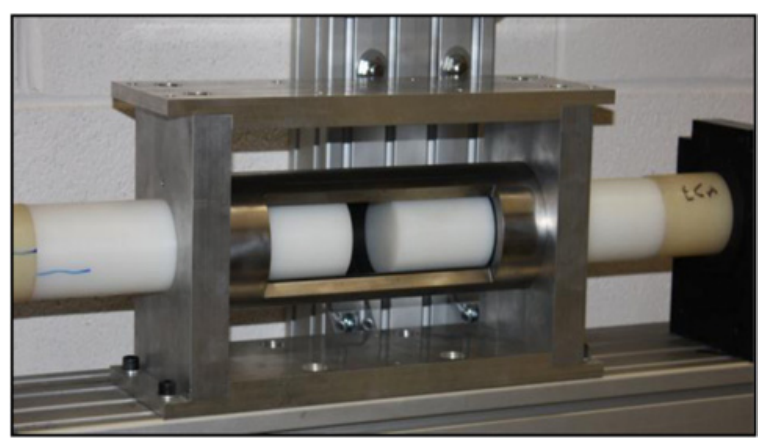

Fig. 6. Combined shear-compression loading device.

measuring of the global force and velocity. Therefore, in ours experiments an electro optical extensometer (Rudolph XR 200) is needed to calculate the shortening of the sample. The main objective is to obtain more information in the stress-strain curve.

\section{Combined shear-compression loading}

SHPB technique is an efficient tool to characterize the material impact behaviour since decades. This technique was used at a first step for metallic materials after works of authors. Zhao and Gary [14] have adapted kolsky technique to characterise many different materials by using a large diameter and viscoelastic bars. The use of the large diameter is performed in order to have a large cross section and a better impedance, to improve the sample/cell size ratio and to reduce the data scatter. Zhao and Gary [14] require some precautions in the wave-shift procedure to valid the elastic waves' system propagating in the viscoelastic bars and to consider the dispersion phenomena due to the large diameter. These requirements are employed to investigate the impact loading test for much kind of cellular materials. In this paper, a typical SHPB set-up composed by two bars $(2 \times 3 \mathrm{~m})$ and a projectile $(1 \mathrm{~m})$ with a same diameter $60 \mathrm{~mm}$ is proposed. The first gauge is placed at midpoint of the input bar and the second is placed at $0.4 \mathrm{~m}$ of the output bar (figure 3 ). The main role of these gauges is to record the three elastic waves after ampli-conditioning process.

\subsection{Combined shear-compression device}

The combined shear-compression device is introduced in the typical SHPB set-up in order to investigate the multiaxial behaviour of cellular material such as honeycomb, hollow sphere, assemblies. This device is composed by two short inclined bars with different loading angle (from 0 to $60^{\circ}$ with an incremental angle equal to $15^{\circ}$ ), coaxial Teflon and steel sleeves and two aluminium supports. Figure 6 shows in details the experimental combined shear-compression loading device. The specimen is placed between the two short beveled bars such as show in figure 6 and 7.

A series of experiments are performed in the axial loading using the typical SHBP set-up (input bar/sandwiched 


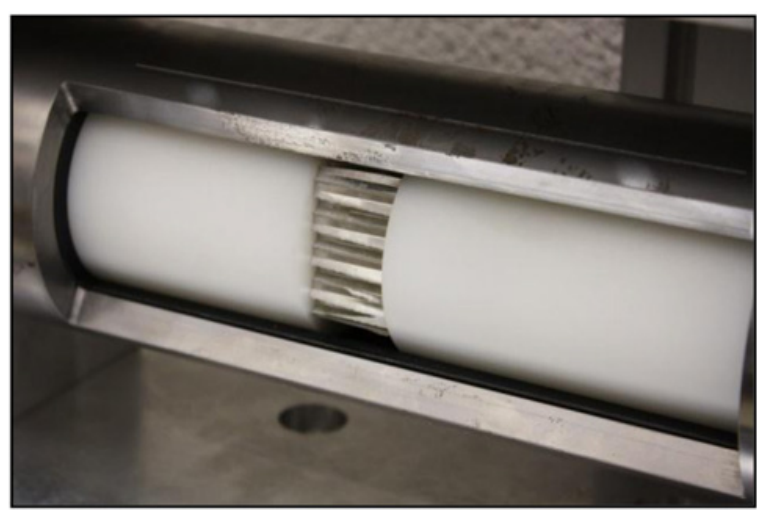

Fig. 7. The combined shear-compression loading device in the axial loading case.

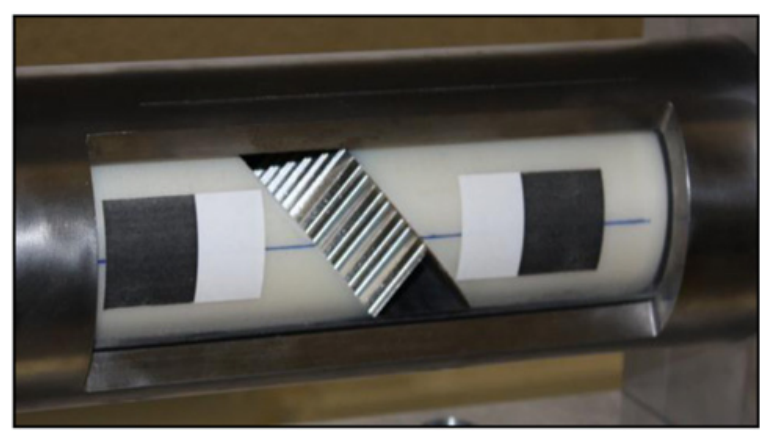

Fig. 8. The combined shear-compression loading device in the multiaxial loading case $\left(\Psi=30^{\circ}\right)$.

specimen/output bar) and others experiments using the device with short inserted bars such as given in figure 6 and 7. The introducing of this device has the same effect mentioned by the numerical study at the measuring of the three elastic waves. The separation phenomenon of the input bar and the input short beveled bar is observed during experimental tests. Aluminium hexagonal honeycomb Al5056-O is used to achieve some experiments under axial and multiaxial loadings (figure 7 and 8). Two cell sizes are employed $(\mathrm{d} 1=6.35 \mathrm{~mm}$ and $\mathrm{d} 2=4.7625 \mathrm{~mm})$, the cell wall thickness is $76 \mu \mathrm{m}$ and $50.8 \mu \mathrm{m}$ respectively. The specimen dimensions are $41 \times 45 \times 25 \mathrm{~mm}$ for Al5056-6$1 / 4-0.003$ and $42 \times 42 \times 25 \mathrm{~mm}$ for A15056-5.7-3/16-0.002.

A projectile launched by a gas gun strikes the free end of the input bar. A compressive longitudinal incident wave $\varepsilon_{i}(\mathrm{t})$ is generated in the input bar. Once this wave reaches the bar/specimen interface, a part of it manned $\varepsilon_{r}(\mathrm{t})$, is reflected, whereas the other part goes through the specimen and develops as the transmitted wave $\varepsilon_{\mathrm{t}}(\mathrm{t})$ in the output bar.

Figure 9 shows these three waves under dynamic axial loading.

Some assumptions should be respected such as the onedimensional wave propagation theory, the homogenous stress and strain fields in the specimen and the inertia effect and the neglected friction between the specimen and the ends of bars. Based on the three elastic waves, the current strain rate, strain and stress of the specimen can be calculated as apparent values:

$$
\dot{\varepsilon}_{s}(t)=\frac{2 C_{D}}{L} \varepsilon_{r}(t)
$$

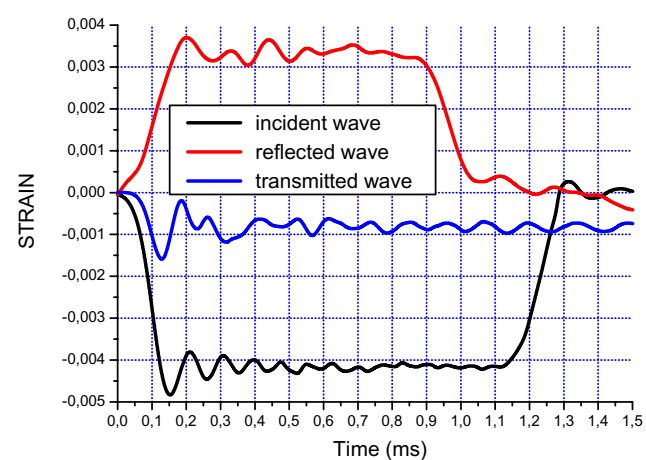

Fig. 9. The three elastic waves under axial loading $\left(\Psi=0^{\circ}\right)$ experimental results.

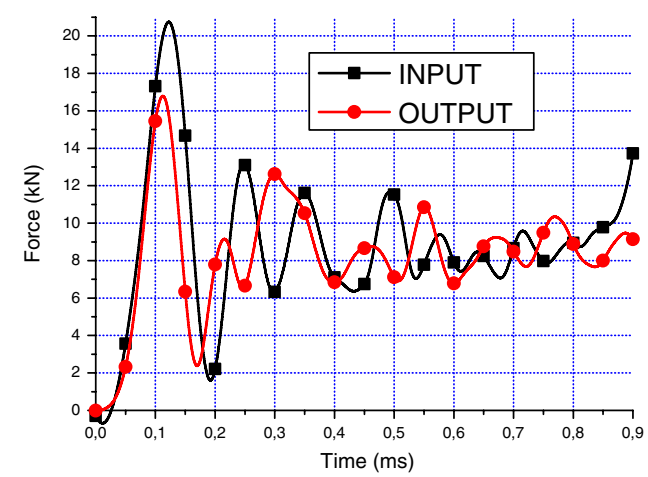

Fig. 10. Input and output forces' equilibrium under axial loading $\left(\Psi=0^{\circ}\right)$.

$$
\begin{gathered}
\varepsilon_{s}(t)=\frac{2 C_{D}}{L} \int_{D}^{t} \varepsilon_{r}(t) d t \\
\sigma_{s}(t)=E\left[\frac{A}{A_{s}}\right] \varepsilon_{t}(t)
\end{gathered}
$$

where $A_{s}$ is the area of specimen cross section, $L$ is the specimen length, $A$ and $E$ are respectively the cross section area and Young's Modulus of Hopkinson bars, $C_{0}$ is the elastic wave speed in bars. In addition, based on the three elastic waves, the input and output forces and velocities can be calculated directly by the following equations:

$$
\begin{gathered}
F_{\text {input }}(t)=A E\left(\varepsilon_{i}(t)+\varepsilon_{r}(t)\right) \\
F_{\text {output }}(t)=A E \varepsilon_{t}(t) \\
V_{\text {input }}(t)=C_{0}\left(\varepsilon_{i}(t)-\varepsilon_{r}(t)\right) \\
V_{\text {output }}(t)=C_{0} \varepsilon_{t}(t)
\end{gathered}
$$

where $F_{\text {input }}(t), F_{\text {output }}(t), v_{\text {input }}(t)$ and $\mathrm{v}_{\text {output }}(t)$ are forces and particle velocities on specimen/bar interfaces in function of time. Figures 10 and 11 show respectively the forces and velocities on the input and output at the interfaces honeycomb specimen and Hopkinson bars under axial compression experiments. 


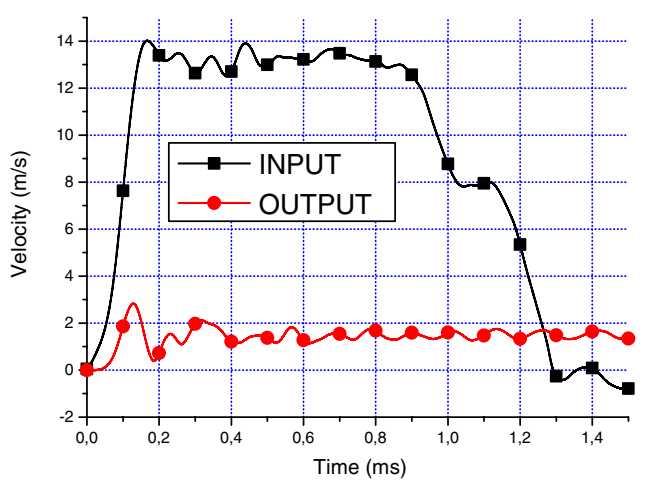

Fig. 11. Input and output velocities under axial loading.

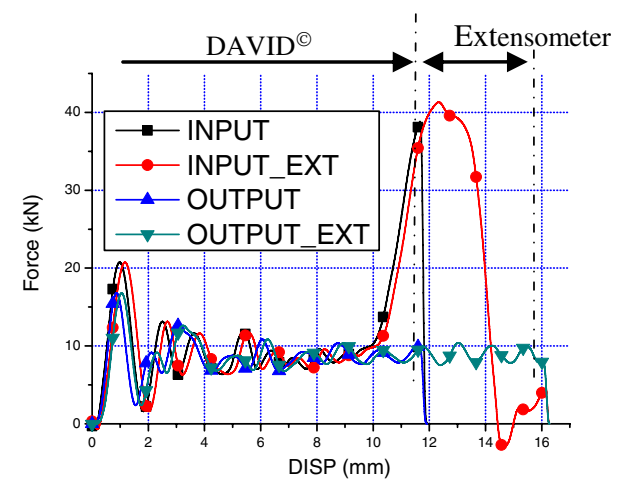

Fig. 12. Comparison between the input and the output forces using David ${ }^{\odot}$ and the extensometer technique $\left(\Psi=0^{\circ}\right)$.

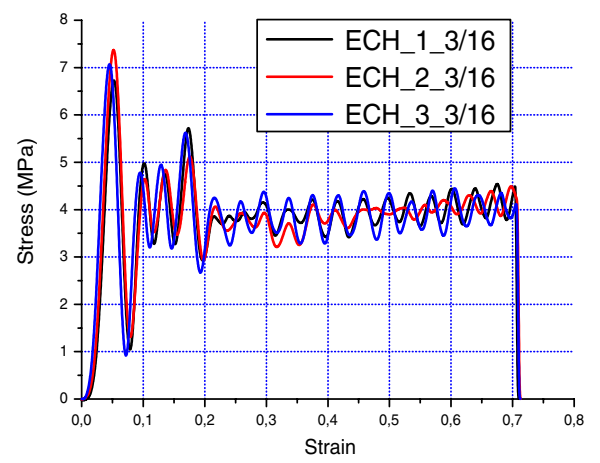

Fig. 13. Comparison between three impact experiments on honeycomb under axial compression loading $\left(\Psi=0^{\circ}\right)$.

\subsection{Effects of beveled bars on data process method}

In order to investigate the influence of the beveled bars on the data calculations, a comparative study is achieved in terms of the three elastic waves recorded directly by the strain gauges cemented on the cylindrical bars.

Due to the separation of the input bar and the input beveled bar during the crash testing and to the limit calculations by David ${ }^{\complement}[15]$. Output forces and shortening of the sample are plotted in function of values provided by output bar and electro-optical extensometer, respectively (figure 12). Three experimental tests per velocity are performed for each loading case (with variation of the loading angle and the orientation angle).

Figure 13 shows the stress/crush curves for $\Psi=$ $0^{\circ}$. The three curves show the same shape with a very

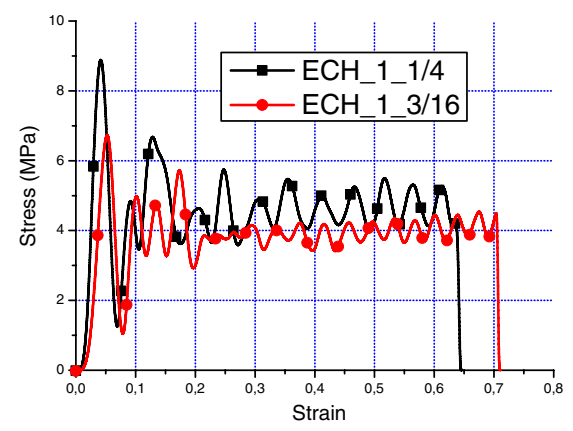

Fig. 14. Comparison between honeycomb with different size cell under axial compression loading $\left(\Psi=0^{\circ}\right)$.

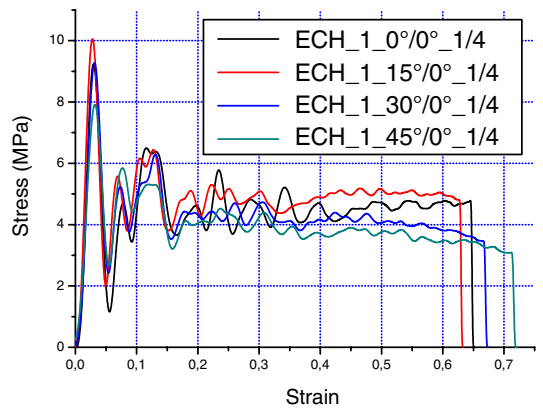

Fig. 15. Comparison between honeycomb with different size cell under axial compression loading $\left(\Psi=0^{\circ}\right)$.

small difference. Therefore, a good repeatability was confirmed for the dynamic loadings using the combined shearcompression device.

Figure 14 shows the influence of the cell size on the stress strain curves. It is found that the stress peak value and the plateau stress of the big size specimen are higher than the one of the small cell size specimen. The deformation mechanisms of these two specimens is almost the same and no effect of the cell size on the mechanisms of deformation that begin by the formation of the first fold and after that a progressive folding system is observed.

The obtained dynamic stress/strain curves show that both the initial peak value and the average plateau stress decrease significantly with the increase of the loading angle (figure 15).

\section{Conclusions and perspectives}

A combined shear-compression loading device is introduced into a large diameter Pa66 SHPB set-up in order to investigate the combined shear-compression behaviour of honeycombs under dynamic loadings. The validation of the process measurement data is achieved by using FE models. A separation phenomenon is observed at the interface input Hopkinson bars/input beveled bar caused an disturbance on the reflected wave. This device is tested and validated in the two cases of loadings: axial and multiaxial. Therefore, it will be used to investigate the effect of the loading angle and the in-plane orientation angle on the deformation mechanisms and multiaxial behaviour of aluminium honeycombs under dynamic and quasi-static loadings, which are intended for further investigations. 


\section{Acknowledgements}

This research is conducted through collaboration between the University of Valenciennes and the National Engineering School of Sfax. This collaboration is jointly financed by the National Centre of Scientific Research and the General Direction of Scientific Research in Tunisia (DGRS-CNRS 11R11-33). The present research work has also been supported by the International Campus on Safety and Intermodality in Transportation, the Nord-Pas-de-Calais region, the European Community, the Regional Delegation for Research and Technology, and by the Ministry of Higher Education and Research. The authors gratefully acknowledge the support of these institutions.

\section{References}

1. L.J. Gibson and M.F. Ashby, Cellular Material: Structure and Properties, second ed. Cambridge University Press, Cambridge, UK. (1997).

2. L. J. Gibson, M. F. Ashby. Cellular Solids. Pergamon Press, Oxford, (1988).

3. M. Y. Yang, J. S. Huang. Elastic buckling of regular hexagonal honeycombs with plateau borders under biaxial compression. Compo. Struct. 71, 229-237 (2005).

4. E. Wu, W. S. Jiang, Axial crush of metallic honeycombs, Int. J. Impact Engng. 19, 439-456 (1997).

5. H. Zhao, G. Gary, Crushing behavior of aluminium honeycombs under impact loading. Int. J. Impact Engng. 21, 827-836 (1998).

6. H. Zhao, I. Elnasri, S. Abdennadher. An experimental study on the behavior under impact loading of metallic cellular materials. Int. J. Mech.Sci. 47, 757-774 (2005).
7. D. Mohr, M. Doyoyo, Nucleation and propagation of plastic collapse bands in aluminium honeycomb. J. Appl. Phy. 94, 2262-2270 (2003).

8. D. Mohr, and M. Doyoyo, Deformation-induced folding systems in thin-walled monolithic hexagonal metallic honeycomb, Int. Journal of Solids and Structures 41, 3353-3377, (2004).

9. D. Mohr, and M. Doyoyo, Experimental investigation on the plasticity of hexagonal aluminium honeycomb under multiaxial loading. J. Appl. Mech. 71, 375-385, (2004).

10. S.T. Hong, J. Pan, T. Tyan and P. Prasad, Quasistatic crush behavior of aluminum honeycomb specimens under compression dominant combined loads, International Journal of Plasticity 22, 73-109, (2006).

11. S.T. Hong, J. Pan, T. Tyan and P. Prasad, Dynamic crush behaviors of aluminum honeycomb specimens under compression dominant inclined loads. Int. J Plasticity 24, 89-117, (2008).

12. B. Hou, A. Ono, S. Abdennadher, S. Pattofatto, Y.L. $\mathrm{Li}$ and $\mathrm{H}$. Zhao, Impact behavior of honeycombs under combined shear-compression. Part I: Experiments, International Journal of Solids and Structures, 48 , 687-697, (2011).

13. B. Hou, S. Pattofatto, Y.L. Li and H. Zhao, Impact behavior of honeycombs under combined shear-compression. Part II: Analysis, International Journal of Solids and Structures. 48, 698-705, (2011).

14. Zhao, H., Gary, G., Klepaczko, J.R., On the use of viscoelastic split Hopkinson pressure bar. Int. J. Impact Eng. 19, 319-330, ( 1997).

15. David, Labview version, User's manual - version > 5048. 